This PDF is a simplified version of the original article published in Internet Archaeology. Enlarged images which support this publication can be found in the original version online. All links also go to the online version.

Please cite this as: Marx, A., Salas Rossenbach, K and Bryas, E. 2021 Digital Archiving and Data Stewardship in French Archaeology, Internet Archaeology 58. https://doi.org/10.11141/ia.58.26

\title{
Digital Archiving and Data Stewardship in French Archaeology
}

Amala Marx, Kai Salas Rossenbach and Emmanuelle Bryas

In France, the archaeological sector has undergone a major shift in the last 10 years in terms of digital data creation and management. The digital transformation of the profession and its practices is still in progress and is not uniform. If general policies and laws are now clearly adopted at a national level, then institutional or individual situations are more complex. We can clearly separate the development-led and academic sectors, with reference to the volume of data produced and the challenges faced. A critical overview of the barriers highlights the fact that, beyond technical issues, data management (specifically sharing) is a human challenge in terms of scientific priority and in the adoption of new practices. This article gives an overview of the main questions and issues with reference to major nationwide initiatives.

\section{Introduction}

Digital data management in French archaeology is not yet a completely clear and stable process. With the upsurge of development-led archaeology, a massive amount of archaeological data is nowadays digitally native but the means of managing and preserving it is still under discussion. We can clearly distinguish two main sectors of activities, in terms of both volume of data and type of digital data managed and archived: development-led/preventive archaeology, and the academic sector. In the first part of this article we will give a broad national overview of the institutional initiatives for managing and archiving archaeological digital data in France. In the second part, we will focus critically on the development-led archaeological sector and, more specifically, on the French National Institute for Preventive Archaeological Research (Inrap), which conducts the vast majority of archaeological activities. 


\section{The National Picture}

Since 2016, the law of 7 October 2016 for a Digital Republic has provided a new legislative framework for making data generated in the framework of public funding or public institutions available. Thanks to this law, the open access to public data, although already practised in certain areas or administrations, is becoming the rule rather than the exception, while ensuring compliance with the legislative and regulatory framework of intellectual property law and personal data protection. The first part of this law specifically concerns the circulation of data and knowledge. One part is also dedicated to the knowledge economy development, with the possibility for researchers to freely publish their scientific articles within six to twelve months. However, this law essentially regulates open access and reuse of data, leaving it up to public institutions to set up infrastructures and data repositories.

In the field of archaeology, institutions and researchers did not wait for this law to come into force to structure the management and preservation of their data. Numerous initiatives and tools have been developed. The Ministry of Culture and its decentralised services responsible for implementing national archaeological policy have set up some digital tools to manage and disseminate archaeological research digital data. Strongly encouraged by the Ministry of Higher Education, Research and Innovation, Universities and CNRS Joint Research Units (Unités Mixtes de Recherche - UMR) working in the field of archaeology have also developed a number of tools and initiatives for the management, dissemination and archiving of digital data resulting from their research. We will attempt to present the most significant ones, highlighting, through our inability to be exhaustive, the lack of a national policy for the management and archiving of digital data produced by our discipline.

\subsection{The archaeological map and geographic information systems}

The Ministry of Culture manages the national archaeological map, which is a mapped inventory of information relating to archaeology within the national territory, from its origins to the present day. The national archaeological map is updated at a regional level by each Regional Archaeology Service (SRA) of the Regional Direction for Cultural Affairs (DRAC) network - decentralised departments of the Ministry of Culture in each French region. It is now managed by the PATRIARCHE application. The SRAs are able to transfer part of the data from the archaeological map to the Atlas des Patrimoines, which is open access. In reality, few services have done so and the data uploaded has not been updated recently. To date, to consult recent data, it is still necessary to visit each SRA. It is, therefore, not easy to have precise knowledge about the data and their quality. For the moment, no link has been established between CAVIAR, a national GIS managed by Inrap (see below), and the Atlas des Patrimoines. In parallel with the Atlas des Patrimoines, the SRA of Bretagne provides the GeoBretagne web application, which allows the general public to view and download part of the archaeological map data (operations, archaeological entities, regulatory zoning, etc.) under an Etalab 2.0 licence. The link 
between the data deposited in the Atlas des Patrimoines and those visible in GeoBretagne is not explicit.

In the field of geographic information systems applied to archaeology, numerous regional or local, thematic or chronological initiatives have emerged over the last decade. We cannot mention them all, but we can emphasise the increasing use of geographic information systems, whether at the level of a research project, a town, a region or a national research institute.

\subsection{Archaeological operation reports}

The ministerial decree of 27 September 2004 strictly regulates the content and form of archaeological operation reports. It also specifies the method of their transfer to the State services. The paper version of the report is the only compulsory one, and the digital version must comply with it. It has to be sent to the Regional Direction for Cultural Affairs (DRAC). The reports may then be consulted in paper (or digital) form in their documentation centres throughout France.

Within the Ministry of Culture, there is no tool for referencing and disseminating archaeological operation reports that allows everyone to have online access to the digital format. In addition to the DOLIA catalogue, managed by Inrap, some regional services have developed, are developing or are planning to develop their own tool. Among the most successful initiatives, we can highlight the DRAC Bretagne one, which decided to publish open access archaeological operation reports (c. 4000 reports), or the DRAC Provence-Alpes-Côte d'Azur one, which has set up a platform that allows online consultation of archaeological operation reports after authentication and a consultation request [https://www.culture.eligis-web.com/]. Other DRAC (Île-de-France, Normandie) are working on publishing their report collections online.

Archiving of paper versions of reports is undertaken in each local archive department, scattered throughout the country. In the absence of a national policy of the State services for long-term preservation, the archiving of reports in digital format remains at the initiative of local managers.

\subsection{Management of archaeological material and artefact-related data}

Similarly, the State has not developed a centralised system for the management of archaeological objects or material and the associated scientific digital documentation. However, each SRA has acquired an IT tool to at least physically manage the archaeological material received at the end of any archaeological operation. We will only mention a few examples, such as Ishtar, a tool developed with public funding, which enables the management, improvement, analysis and sharing of data from archaeological operations, from the field to the museum. In another part of France, the Syslat system is used. It is a set of free tools for managing archaeological excavation data (from field recording to the management of 
the documentation and objects). In south-east France, a database for material and artefact management called Sisyphe has been developed, but it is little used and not finalised. Other regional archaeological services have chosen to develop databases with Filemaker Pro or simple Excel spreadsheets.

Once again, there is great diversity in the IT tools used to manage archaeological material and associated documentation by the State's own departments. The establishment of shared preservation centres (museums, universities, associations, development-led archaeology operators, etc.) for all documentation resulting from archaeological operations, both excavation archives and inventoried archaeological material, throughout France would certainly allow the adoption of common or at least interoperable tools.

\subsection{Other tools and technical infrastructure}

Over the last decade, the digital environment of archaeological research in French academic circles has grown considerably. Although the involvement in academic research of archaeologists working in development-led archaeology is increasingly important, it remains difficult, despite numerous collaborations, to develop shared tools. However, there are exceptions and the willingness of part of the community to offer a viable digital context to archaeology, whether development-led or academic, gives hope for a more interoperable future.

The Frantiq network, for example, brings together about 40 members, both in the field of development-led archaeology and academic archaeology. For 30 years, in compliance with international norms and standards of library science and ontologies, it has been developing a common bibliographic catalogue for the various partners, the 'Catalogue Collectif Indexé' as well as PACTOLS, an archaeology-themed thesaurus for the scientific and academic community. PACTOLS is the main French thesaurus in archaeology, polyhierarchical, multilingual and scalable, in accordance with the FAIR principles, and is widely used by the French archaeological community.

Financed by the Ministry of Higher Education, Research and Innovation, the general objective of the TGIR Huma-Num is to 'facilitate the digital turn in the humanities and social sciences research'. By encouraging the creation of field-specialised consortia, Huma-Num enhances scientific community building. Several consortia include archaeology in their approach (3D consortium, Medieval Sources Consortium COSME, Paris Time Machine); the Consortium Mémoires des archéologues et des sites archéologiques (MASA), in which Inrap participates, is entirely dedicated to it. This consortium works on digital data stewardship in archaeology and preservation. The challenge is threefold: to work on the data processing, to work on making it accessible and preserving it, and finally to encourage sharing and reuse. In addition to training and dissemination of good practices, a data management plan template for archaeological research projects has been developed. Within the framework of this consortium, the CITERES laboratory in Tours has also designed the OpenArchaeo platform, which aims to make archaeological datasets produced within the MASA consortium available on the semantic web and to offer an intuitive 
query interface for archaeological data, inspired by the ResearchSpace search engine set up by the British Museum.

In addition to its support to consortia, the TGIR Huma-Num relies on a technical infrastructure that offers sustainable digital tools and services on a national and European scale by relying on a large network of partners and operators. Huma-Num does not offer a search engine, nor a scientific editorial website, nor a data enrichment system. Its objectives are to propose solutions to host, to disseminate and to preserve the data produced by humanities and social sciences research projects. Several archaeological research projects use Huma-num services; it is difficult, however, to evaluate the proportion properly. In the field of development-led archaeology, because of the large amount of data produced, these services remain difficult to use on a large scale.

\subsection{Sharing scientific publications}

In 2001, the CNRS developed an online platform $\underline{H A L}$ for referencing and disseminating published or unpublished articles, photographs and research work. It takes time for archaeological researchers to adopt this platform but for several years, it has been widely used in the community. Any document deposited in HAL has a unique and permanent URL and is archived in a sustainable way at the Centre Informatique National de l'Enseignement

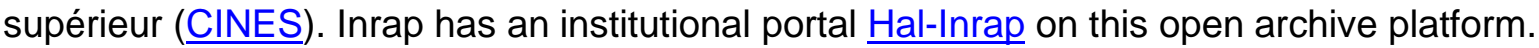
In 2020, the project 'Peer Community in Archaeology' or PCl Archaeology was created. This is a new peer review system for academic manuscripts in archaeology already deposited on preprint servers. The preprints recommended by $\mathrm{PCl}$ are full papers, they are scientifically validated and can be cited without the need to publish them in traditional scientific journals.

\section{Inrap and Development-led Archaeology}

In January 2001, a law on preventive archaeology was put into effect in France. This law introduced a tax designed to fund preventive archaeology evaluations and excavations. It also presaged the creation of a public administrative body, the Institut National de Recherches Archéologiques Préventives (French National Institute for Preventive Archaeological Research), established in February 2002. Inrap is responsible for carrying out all the operations prescribed by the local SRA (Ministry of Culture). In August 2003, a new law put an end to Inrap's monopoly on preventive archaeology operations. Archaeological evaluations remain a public prerogative but can be carried out either by Inrap or local government services. The excavations are open to competition; Inrap and accredited public and private operators can compete. The entire procedure is supervised by the State.

About 3000 development-led archaeological excavations take place each year (including both evaluations and large-scale excavations). These lead to the production of digital data at every stage: in the field with recording systems that compile the data collected; spatial data in the form of GIS; documentation for the management of the archaeological material unearthed; visual material in the form of photographs and 3D images, for example; and above all, in the form of excavation 
reports that complete the process, and in the form of thematic research publications. At Inrap, more than 2000 excavation reports are produced each year. The Institute has developed information systems that cover all or part of the management of these data. For example, CAVIAR is a geographic information system for the entire institution; COMODO is a tool for managing and locating archaeological artefacts and the scientific documentation associated with it; and DOLIA reports, describes and locates the scientific documentation kept by the Institute, and makes Inrap's excavation reports available, whether these are born-digital or digitised versions of legacy analogue reports (c. 42,000 reports referenced). At present, through DOLIA only a selection of excavation reports is available online and open to sharing on the web.

The data management, archiving and sharing policy of the other development-led archaeology operators (public or private) is difficult to identify. Some of them only offer a minimal cartographic online service that summarises their operations.

The dynamics of opening and sharing data, supported by the European and national levels, in particular the Ministry of Research, naturally crosses the development-led archaeology sector. The stakes are all the more important, as it is in this disciplinary area that the vast majority of digital data produced in archaeology is concentrated. Inrap, as the central institute of the system, is in the process of developing a proactive policy for sharing the data resulting from its research. The objective is to move towards processes and datasets that comply with the FAIR principles. To follow this path, the entire process of creation, management and archiving is being transformed towards the formalisation of a natively digital and ultimately shareable data cycle.

This necessary development, which must be extended to all those involved in commercial or public development-led archaeology, raises profound professional questions. We will introduce three that regularly arise. The digital transformation of the institution and the sector raises the question of its consequences for the organisation of development-led archaeology work, from the field to publication. Certain practices are being significantly changed (field recording, editorial processes), and new jobs are being created (data managers, and in the future data analysts). The question of new strategies for recruiting and training staff is a key element whose structure has not yet stabilised. The sharing of data from development-led archaeology operations raises the question of scientific priority. As in the United Kingdom, there is a very marked dichotomy in the time spent on scientific study and publication between the academic sector and the developmentled archaeology sector. Thus, archaeological researchers in development-led archaeology sometimes have less time to devote to the scientific formalisation of fieldwork than full-time research colleagues employed by other institutions. The question of data sharing thus seems to involve a risk for the former with regard to the scientific priority given certain data. This is a major issue in terms of the acceptability of the digital transformation and professional respect. It is therefore necessary to build sharing systems that comply with the FAIR principles and that allow archaeologists in the development-led sector to publish their work and, at the very least, to ensure that scientific citation is respected. These points are fundamental for the entire discipline to avoid falling definitively into a 'producers vs processors' model that does not correspond to the spirit and the letter of the law on development-led 
archaeology. A third element of vigilance particularly concerns the sharing of geolocalised data in the context of the development of site looting and metal detecting, both prohibited by French law. The strict application of the FAIR principles must be confronted with the imperative of heritage preservation.

French development-led archaeology has made the digital data resulting from its research, in particular through Inrap, open access. The strategy of not delegating this activity to external players but building a management and sharing model adapted to the processual, legal and human context of development-led archaeology is undoubtedly the right path. Inrap's immersion in European and international digital archiving discussions through its participation in European projects and networks (e.g. ARIADNEPlus), coupled with its presence in most national networks, has enabled the Institute to position itself to be a national driving force in the matter. The challenge facing the sector is clearly at two levels. At the level of national institutional policies, the various stakeholders (particularly private operators) must take a definitive position on the need to share archaeological data. Furthermore, at the human level, the greatest challenge lies in the form of change management, which will upset professional and reputational practices and positions. Whatever the adaptations, delays or reticence, the digital data resulting from archaeological research must and will be shared with as many people as possible in the spirit of the sector's public service mission.

\section{Conclusion}

The generalised use of computer tools and new technologies for data acquisition and processing at all stages of archaeology (from the collection of data in the field to their study, analysis and publication in the form of a site monograph or synthesis) has led to an exponential increase in the mass of digital data produced in France. For many years, their eventual conservation was the sole responsibility of the researcher. It is only recently, within the last 10 years at most, that the different institutions have started to think about an institutional policy of digital data management.

The implementation of these policies has to address three challenges:

- the multiplicity of practices that makes it difficult to standardise data, which may in any case not necessarily be desirable, to facilitate their archiving;

- the considerable volume of legacy data over the last 30 years, which are now dispersed, disappearing, and disparate;

- the difficulty of establishing criteria to select the data to be preserved. However, these criteria are indispensable, as the considerable mass of digital data produced by an operation makes it impossible and unnecessary to preserve everything.

Various projects have been launched, some of which have been successful, but no French archaeological institution today can yet say that it perfectly manages its digital data from production to long-term preservation and dissemination. 


\section{Bibliography}

Loi № 2001-44 du 17 janvier 2001 relative à l'archéologie préventive (J.O. 18 janvier 2001). https://www.legifrance.gouv.fr/loda/id/JORFTEXT000000221337/ [Last accessed: 29 October 2021].

Loi № 2003-707 du 1er aout 2003 modifiant la loi № 2001-44 du 17 janvier 2001 relative à l'archéologie préventive (J.O. 2 août 2003). https://www.legifrance.gouv.fr/jorf/id/JORFTEXT000000428978/ [Last accessed: 29 October 2021].

Loi №2016-1321 du 7 octobre 2016 pour une République numérique (J.O. 8 octobre 2016). https://www.legifrance.gouv.fr/loda/id/JORFTEXT000033202746?init=true\&pa ge $=1$ \&query=loi+republique + num\%C3\%A9rique\&searchField=ALL\&tab selection=al I [Last accessed: 9 September 2021].

Arrêté ministériel du 27 septembre 2004 portant définition des normes de contenu et de présentation des rapports d'opérations archéologiques. https://www.legifrance.gouv.fr/eli/arrete/2004/9/27/MCCB0400702A/ jo/texte [Last accessed: 9 September 2021]. 